\title{
Hemostatic markers are associated with the risk and prognosis of atrial fibrillation: the ARIC study
}

\author{
Alvaro Alonso, MD, PhD1, Weihong Tang, MD, PhD1, Sunil K. Agarwal, MD², Elsayed Z. \\ Soliman, MD, MS ${ }^{3}$, Alanna M. Chamberlain, $\mathbf{P h D}^{1}$, and Aaron R. Folsom, MD, MPH ${ }^{1}$ \\ ${ }^{1}$ Division of Epidemiology and Community Health, School of Public Health, University of \\ Minnesota, Minneapolis, MN \\ ${ }^{2}$ Department of Epidemiology, Gillings School of Global Public Health, University of North \\ Carolina, Chapel Hill, NC \\ ${ }^{3}$ Department of Epidemiology, Division of Public Health Sciences, Wake Forest University School \\ of Medicine, Winston-Salem, NC
}

\section{Abstract}

Background-Various hemostatic markers are associated with the risk of cardiovascular disease; however, limited information exists on their relationship with the occurrence and prognosis of atrial fibrillation (AF).

Objectives-To assess whether hemostatic markers are associated with the incidence and prognosis of AF.

\begin{abstract}
Methods-We studied 14,858 men and women in the Atherosclerosis Risk in Communities cohort, aged 45-64 and free of AF at baseline (1987-1989). Fibrinogen, von Willebrand factor (vWf), factor VII activity (VIIc), factor VIII activity (VIIIc), protein C, antithrombin III (ATIII), and activated partial thromboplastin time (aPTT) were measured in blood samples at baseline. AF and other cardiovascular outcomes through 2005 were determined following standardized protocols.
\end{abstract}

Results-During a median follow-up of 16.8 years, 1209 cases of AF were identified. In multivariable Cox models, the hazard ratios (HR) and 95\% confidence intervals (CI) of incident $\mathrm{AF}$ associated with a 1-standard deviation (SD) increase in each marker were $1.13(1.07-1.20)$ for fibrinogen, 1.17 (1.11-1.23) for vWf, $1.17(1.11-1.24)$ for factor VIIIc, $0.93(0.88-1.00)$ for factor VIIc, $0.98(0.92-1.04)$ for protein C, $1.00(0.94-1.06)$ for aPTT and $1.00(0.95-1.06)$ for ATIII. Greater factor VIIIc, fibrinogen and vWf were consistently associated with a higher risk of cardiovascular outcomes and mortality in those with and without incident AF, while greater protein $\mathrm{C}$ was associated with a lower risk of ischemic stroke.

() 2010 Elsevier Ireland Ltd. All rights reserved

Corresponding author: Alvaro Alonso, MD, PhD. Division of Epidemiology and Community Health, School of Public Health, University of Minnesota. 1300 S 2 ${ }^{\text {nd }}$ St, Suite 300. Minneapolis, MN 55454, USA. Phone: +1 612626 8597. Fax: +1 6126240315. alonso@umn.edu.

Publisher's Disclaimer: This is a PDF file of an unedited manuscript that has been accepted for publication. As a service to our customers we are providing this early version of the manuscript. The manuscript will undergo copyediting, typesetting, and review of the resulting proof before it is published in its final citable form. Please note that during the production process errors may be discovered which could affect the content, and all legal disclaimers that apply to the journal pertain.

DISCLOSURES The authors have no conflicts to disclose 
Conclusion-Several hemostatic markers are associated with the incidence of AF independently of other cardiovascular risk factors. Their role in the risk stratification of AF patients should be further studied.

\section{Keywords}

atrial fibrillation; epidemiology; prognosis; fibrinogen; von Willebrand factor

\section{INTRODUCTION}

Atrial fibrillation (AF), the most common cardiac arrhythmia in clinical practice, is expected to affect more than 12 million Americans by $2050 .{ }^{1}$ Though our knowledge of the etiology of AF is limited, previous research has described a number of risk factors and predictors of incident $\mathrm{AF}$ in the general population, including traditional cardiovascular risk factors and novel biomarkers, such as C-reactive protein or natriuretic peptides. ${ }^{2-4}$ Different lines of evidence suggest that markers of hemostatic function could also be associated with the new onset of AF. For instance, risk of coronary heart disease, an established risk factor for AF, is higher in individuals with higher levels of von Willebrand factor and fibrinogen. ${ }^{5,6}$ Also, individuals with paroxysmal episodes of AF, some of them clinically undetected, might experience changes in blood levels of hemostatic markers, ${ }^{7}$ which in turn could predict the clinical diagnosis of AF. Finally, some hemostatic markers reflect other pathophysiological processes. Fibrinogen and von Willebrand factor are markers of inflammation and endothelial dysfunction, respectively. Both pathophysiological pathways might increase AF risk, directly or through an elevated risk of overall cardiovascular disease. ${ }^{5,8}$ Alternatively, activated protein $\mathrm{C}$ has anti-inflammatory and anti-apoptotic effects, and stabilizes the endothelial barrier, ${ }^{9}$ mechanisms that could prevent the development of the AF substrate. ${ }^{8}$, ${ }^{10}$ Among hemostatic markers, fibrinogen was associated with AF risk in the Copenhagen City Heart Study, ${ }^{11}$ but not in the Framingham Offspring Study. ${ }^{12}$ In addition, the later study did not find associations of D-dimer or plasminogen activator inhibitor type 1 with $\mathrm{AF}$ risk, but the number of $\mathrm{AF}$ events was limited. ${ }^{12}$

Individuals with AF have an increased risk of stroke and overall mortality. ${ }^{13}$ Stroke is a severe and frequent complication of $\mathrm{AF}$, facilitated by the lack of efficient atrial contraction and consequent increased thrombogenesis. ${ }^{14}$ Therefore, markers of hemostasis might predict the future risk of thromboembolic complications in AF patients, but support for this hypothesis is limited to studies with relatively small sample sizes and short follow-up. ${ }^{15-17}$

Available evidence, thus, suggests that markers of hemostatic function could be related to an increased risk of AF. To evaluate this question, we studied the association of hemostatic markers with the incidence of AF in a large population-based cohort in the United States. As a secondary aim, we explored whether hemostatic markers predicted differently the risk of stroke, cardiovascular disease or mortality in individuals with and without incident AF.

\section{METHODS}

\section{Study population}

The Atherosclerosis Risk in Communities (ARIC) cohort is a large prospective study aimed to identify risk factors of atherosclerosis and cardiovascular disease. A detailed description of the ARIC cohort can be found elsewhere. ${ }^{18}$ Briefly, 15,792 men and women aged 45-64 from four communities in the United States (Jackson, Mississippi; Forsyth County, North Carolina; Washington County, Maryland; suburbs of Minneapolis, Minnesota) were recruited and examined in 1987-1989. The Jackson site recruited only African-Americans. The racial composition of the cohort in the other three field centers reflected the underlying 
population, mostly whites in the Minneapolis and Washington County sites, and whites and African-Americans in Forsyth County. Study participants were re-examined in three followup visits, each three years apart. Additionally, they have been contacted by phone every year since baseline. More than $90 \%$ of the surviving cohort continues to respond to the annual follow-up phone calls. Institutional Review Boards at all participating institutions approved the ARIC study. All study participants provided written informed consent.

For this analysis, we excluded individuals with prevalent $\mathrm{AF}$ at baseline, determined by electrocardiogram (ECG) $(n=37)$, those with unreadable or no $E C G$ at baseline $(n=310)$, those taking anticoagulant therapy $(\mathrm{n}=90)$, and those without hemostatic markers information ( $n=265)$ or missing information for other covariates $(n=390)$. Additionally, we excluded a small group of nonwhites in the Minnesota and Washington County sites and those not white or African-American in the Forsyth County site ( $n=103)$. After applying exclusion criteria, 14,858 participants were eligible for the follow-up.

\section{Measurement of hemostatic markers}

Blood was collected at baseline after an 8-hour fasting period. Samples were processed following a standardized protocol and stored at $-70^{\circ} \mathrm{C}$ for a few weeks until assayed. Detailed methods for blood processing and measurement of hemostatic markers have been published previously. ${ }^{19,}{ }^{20}$ Fibrinogen was measured by the thrombin-time titration method; factor VII activity (VIIc) and factor VIII activity (VIIIc) by clotting assays; von Willebrand factor antigen and protein C antigen by ELISA; antithrombin III (ATIII) activity by a chromogenic substrate method; and activated partial thromboplastin time (aPTT) on an automated coagulometer. Reliability coefficients obtained from repeated testing on a sample of subjects over several weeks were 0.72 for fibrinogen, 0.78 for factor VIIc, 0.86 for factor VIIIc, 0.68 for von Willebrand factor, 0.56 for protein C, 0.42 for ATIII, and 0.92 for aPTT. 21

\section{Ascertainment of atrial fibrillation and other cardiovascular events}

AF in ARIC was ascertained from three different sources: ECGs performed at baseline and at each follow-up visit; hospital discharge codes; and death certificates. ${ }^{22,}{ }^{23}$ During each study visit, a standard supine 12-lead resting ECG recording was done with MAC PC Personal Cardiographs, and transmitted to the ARIC Central ECG Reading Center for coding, interpretation, and storage. ECG recordings automatically coded as AF were visually re-checked by a cardiologist. ${ }^{24}$ Additionally, all hospitalization discharges and death certificates from baseline through December 2005 including an ICD code for AF (ICD-9: 427.31 or 427.32, ICD-10: I48) were considered events. Validity of hospital discharge codes is close to $90 \%$ in the ARIC cohort, ${ }^{22}$ and almost $100 \%$ in other similar settings. ${ }^{25}$ Individuals with atrial flutter were classified as AF cases. Episodes of AF occurring in the context of cardiac surgery were not considered events.

New stroke and coronary heart disease events during the follow-up were ascertained according to published methodology. ${ }^{26,} 27$ Cohort participants are contacted annually by phone and interviewed about hospitalizations in the previous year. Trained abstractors collected information on all hospitalizations involving stroke or cardiovascular disease. Mortality was ascertained through annual phone calls, ongoing surveillance of health department death certificate files, search of hospital records, and the National Death Index. Death certificates were also reviewed to identify additional cases of cardiovascular disease. Events were classified following expert review and the application of standard criteria. For the purpose of this analysis, a coronary heart disease (CHD) event was defined as a definite or probable hospitalized myocardial infarction or a definite coronary heart disease death, while ischemic stroke was defined as any definite or probable ischemic stroke episode. ${ }^{26,27}$ 


\section{Assessment of other variables}

At baseline, study participants completed questionnaires collecting information on their medical history, education, income, use of medication, smoking, and alcohol intake. Sportsrelated physical activity was assessed by the Baecke questionnaire. ${ }^{28}$ Weight and height were measured by trained technicians following a standardized protocol, with the participant wearing a light scrub and no shoes. Sitting blood pressure was taken 3 times with a random zero sphygmomanometer, with the average of the 2 last measurements considered the participant's blood pressure. Blood cholesterol and glucose were measured according to standardized methods. ${ }^{18}$

\section{Statistical analysis}

The association of hemostatic markers with the risk of incident $\mathrm{AF}$ was estimated with a Cox proportional hazards model with time to AF as the main independent variable. Followup time was calculated as the time elapsed between the baseline visit to the first diagnosis of AF, death or December 31, 2005, whichever occurred earlier. Models were run for each hemostatic marker separately. In an initial model, we included the hemostatic marker (categorized in quartiles, calculated from the entire eligible sample), age, race and sex. In a second model, we added potential confounders for this association: body mass index (continuous), height (continuous), education (categorical), income (categorical), study site (categorical), cigarette smoking (current, past, or never smoking), alcohol intake (continuous), sports-related physical activity (continuous), systolic blood pressure (continuous), use of antihypertensive medication (categorical), diabetes (categorical), total cholesterol (continuous), HDL cholesterol (continuous), use of lipid-lowering medication (categorical), and ECG-based left ventricular hypertrophy (categorical). Finally, in a third model, we additionally adjusted for prevalence of heart failure and myocardial infarction at baseline, as potential mediators of the association between hemostatic markers and AF risk. We repeated these analyses including the hemostatic markers as a continuous variable and estimated the hazard ratio (HR) of AF associated with a difference of 1 standard deviation (SD) in the marker. In separate analyses, we categorized hemostatic markers using the percentiles $90^{\text {th }}$ and $95^{\text {th }}$ (or $5^{\text {th }}$ and $10^{\text {th }}$ for factors showing inverse associations with $\mathrm{AF}$ ). We additionally estimated the joint association of fibrinogen and von Willebrand factor, and of factor VIIIc and von Willebrand factor with the incidence of AF creating 9 categories of exposure based on cross-classification by tertiles of these hemostatic markers. Finally, we conducted analyses stratified by gender, age $(\geq 55,<55)$, race, and prevalence of CVD at baseline. The proportionality of the hazards was tested adding to the model an interaction term between follow-up time and exposure of interest.

We carried out several sensitivity analyses to evaluate the robustness of our results to changes in the AF definition. First, we repeated the analysis including only cases of AF identified from ECGs done during the three follow-up visits. Second, we estimated the risk of AF censoring a participant if she or he was hospitalized with a definite or probable myocardial infarction. Third, we excluded individuals who developed AF in the first 5 years of follow-up, to avoid including cases with prevalent but undetected paroxysmal AF at baseline.

Finally, we determined whether associations of hemostatic markers with risk of stroke, coronary heart disease and mortality were similar in individuals with or without AF. To this purpose, we selected ARIC participants free of stroke, myocardial infarction, heart failure and $\mathrm{AF}$ at baseline, adding incidence of $\mathrm{AF}$ as a time-varying exposure in Cox models and adjusting for potential confounders measured at baseline. Three separate sets of analyses were conducted, using three different outcomes: ischemic stroke, CHD, and death. As with the primary analysis, follow-up was defined as the time elapsed since baseline to the event 
of interest, death, or December 31, 2005. Initial models were adjusted for age at baseline, gender and race. Subsequent analyses were adjusted for the same variables included in multivariate analyses described above.

\section{RESULTS}

Table 1 reports baseline characteristics of the 14,858 participants according to race and incidence of AF. Compared to those who did not develop AF during the follow-up, those who did were older, more likely to be men, smokers, hypertensive, or diabetic, and had higher body mass index and higher levels of von Willebrand factor, fibrinogen and factor VIIIc. Additionally, they were more likely to have a history of myocardial infarction or heart failure.

During a median follow-up of 16.8 years (percentile $25^{\text {th }} 16.0$, percentile $75^{\text {th }} 17.7$ ), 1209 new cases of AF were identified. The main source of case ascertainment was hospital discharge codes (93.9\%), followed by ECGs at study visits (9.6\%), with only a small number identified through death certificates $(0.6 \%)$. One hundred and five cases $(8.4 \%)$ were identified through more than 1 source.

AF incidence was strongly associated with several hemostatic markers (table 2). Individuals with higher levels of fibrinogen, factor VIIIc, and von Willebrand factor had higher risk of $\mathrm{AF}$, even after adjustment for a number of confounders and potential mediators, including history of heart failure or myocardial infarction at baseline. Higher factor VIIc was associated with a lower risk of AF, but only in multivariable models. Results were very similar when we excluded AF incident cases occurring in the first 5 years of follow-up $(\mathrm{n}=184)$ (data not shown). Table 3 presents results comparing AF risk among those with extreme values (defined as $\geq 90^{\text {th }}$ percentile or $\geq 95^{\text {th }}$ percentile for fibrinogen, factor VIIIc, von Willebrand factor, aPTT and ATIII, and $\leq 5^{\text {th }}$ or $\leq 10^{\text {th }}$ percentile for protein C and factor VIIc) compared to the rest of the sample. Results were similar to those obtained in the quartile analysis. In addition, low levels of protein $\mathrm{C}$ (below the $5^{\text {th }}$ percentile, $\leq 2.3 \mu \mathrm{g} / \mathrm{mL}$ ) were associated with a higher risk of AF (HR 1.33, 95\% 1.07-1.65).

Von Willebrand factor was associated with AF incidence independently of fibrinogen (figure 1A) and factor VIIIc (figure 1B). In multivariable models including von Willebrand factor and fibrinogen simultaneously, HRs $(95 \% \mathrm{CI})$ of $\mathrm{AF}$ associated with 1-SD increase were 1.15 (1.09-1.21) for von Willebrand factor and 1.10 (1.04-1.17) for fibrinogen. Corresponding HRs $(95 \% \mathrm{CI})$ for $\mathrm{AF}$ in a model including von Willebrand factor and factor VIIIc were $1.10(1.02-1.19)$ and $1.10(1.01-1.18)$, respectively. The associations of factor VIIc and protein $C$ with AF were also independent of each other even though both markers were moderately correlated $(\mathrm{r}=0.41, \mathrm{p}<0.0001)$. Adjusting for protein $\mathrm{C}$ levels and multiple covariates, the HR $(95 \% \mathrm{CI})$ of $\mathrm{AF}$ in those with factor VIIc $\leq 5^{\text {th }}$ percentile compared to those $>5^{\text {th }}$ percentile was $1.24(0.96-1.60)$, while the corresponding HR for protein $\mathrm{C}$ adjusting for factor VIIc levels was $1.30(1.04-1.61)$.

The results did not appreciably change when follow-up was censored at the time a study participant was hospitalized with a definite or probable myocardial infarction (supplement table 1). In an analysis including only AF cases identified through ECGs done at follow-up visits ( $\mathrm{n}=116$ cases), factor VIIc and protein $\mathrm{C}$ were inversely associated with the incidence of AF, but no associations were found for other hemostatic markers (supplement table 2).

Analyses stratified by age, race, gender or baseline history of CVD provided overall similar results (supplement table 3). The only exceptions were factor VIIc, which was inversely associated with $\mathrm{AF}$ in young but not older individuals (HR, 95\% CI, for 1-SD increase in $<55$ year old participants $0.82,0.73-0.92$, and in $\geq 55$ year old $0.99,0.91-1.07$, p for 
interaction $=0.04$ ) and von Willebrand factor, which was a stronger predictor of $\mathrm{AF}$ in women than in men (HR, 95\% CI, for 1-SD increase in women 1.26, 1.17-1.36, and in men $1.09,1.01-1.18, \mathrm{p}$ for interaction $=0.007)$.

Finally, we assessed whether hemostatic markers were similarly associated with incidence of ischemic stroke, CHD, or total mortality in those who developed AF prior to cardiovascular events during the follow-up and those who did not. In an analysis including AF incidence as a time-varying exposure and stratifying by AF incidence, hemostatic markers presented similar associations in both groups (table 4). From 585 incident ischemic strokes, 1218 CHD events, and 2398 deaths, 55, 70 and 318 respectively occurred after AF incidence. Greater factor VIIIc, fibrinogen and von Willebrand factor at baseline were consistently associated with a higher risk of cardiovascular outcomes and mortality in individuals with and without incident $\mathrm{AF}$, while protein $\mathrm{C}$ was associated with an inverse risk of ischemic stroke. No clear associations were observed for aPTT, ATIII and factor VIIc (table 4).

\section{DISCUSSION}

In this ethnically diverse, middle-aged population, higher levels of fibrinogen, factor VIIIc, and von Willebrand factor were associated with a higher risk of incident AF, while protein $\mathrm{C}$ and factor VIIc were associated inversely with AF incidence. In addition, all of these except factor VIIc were similarly associated with the risk of stroke, coronary heart disease and overall mortality in individuals with and without AF.

Ours is the first prospective study to report the association of a large panel of hemostatic markers and the risk of AF. Two previous publications explored whether fibrinogen was related to the risk of $\mathrm{AF}$, with inconsistent results. In the Copenhagen City Heart Study, which identified $286 \mathrm{AF}$ cases in 8870 participants, the $\mathrm{HR}(95 \% \mathrm{CI})$ of $\mathrm{AF}$ in the highest versus the lowest quartile of fibrinogen was 2.07 (1.29-3.32). ${ }^{11}$ However, in an analysis of 3120 participants of the Framingham Offspring Study, including 209 incident cases of AF, fibrinogen was not associated with the incidence of AF (HR, 95\% C 1.09, 95\% CI 0.941.26, for 1-SD increment). ${ }^{12}$ The later study did not find associations of D-dimer or plasminogen activator inhibitor type 1 with AF risk. ${ }^{12}$

Different mechanisms could explain the association of hemostatic markers with higher AF risk. Fibrinogen is a known marker of inflammation, a potential pathogenic pathway potentially leading to AF. ${ }^{8}$ Similarly, elevated von Willebrand factor is considered a marker of endothelial dysfunction, ${ }^{29}$ which leads to oxidative stress, inflammation and atherosclerosis, ${ }^{30}$ indirectly predisposing to $\mathrm{AF}$. Von Willebrand factor, also, has been associated with some risk factors for $\mathrm{AF}$, such as diabetes. ${ }^{31}$ The association of AF risk with factor VIIIc could be due to the strong correlation between the latter and von Willebrand factor levels.

Low levels of protein $\mathrm{C}$ and factor VIIc were associated with increased incidence of AF. Protein $\mathrm{C}$ is an anti-thrombotic factor, but also has anti-inflammatory and anti-apoptotic effects, mediated by the protein-activated receptor-1 (PAR-1) signaling pathway. ${ }^{9}$ Protein C, through these mechanisms, could prevent the development of atrial fibrosis, the substrate for AF. It is unclear, however, how factor VIIc could be associated with lower risk of AF. Factor VII, like protein $\mathrm{C}$, is a ligand for the endothelial protein $\mathrm{C}$ receptor (EPCR) ${ }^{32}$ but, in contrast to protein C, factor VII binding to EPCR does not activate the PAR-1 pathway, ${ }^{33}$ and has an overall procoagulant effect.

Reverse causation bias might explain our observations. Undiagnosed paroxysmal AF in ARIC participants at baseline could create a prothrombotic state, ${ }^{14}$ with higher levels of 
markers such as fibrinogen and von Willebrand factor, ${ }^{34}$ or lower protein C. However, an analysis excluding AF cases identified in the first 5 years of follow-up-more likely to have undetected prevalent paroxysmal $\mathrm{AF}$ - provided comparable results.

Previous studies have reported associations of fibrinogen, factor VIIIc, von Willebrand factor, and protein $\mathrm{C}$ with incidence of stroke and CHD in the general population. ${ }^{5}, 35,36$ Similar evidence for individuals with AF is limited to relatively small studies or with short follow-up, but still indicative of a relation between hemostatic markers and cardiovascular outcomes in AF patients. ${ }^{15,16}$ Our results further suggest that these associations equally apply to individuals with and without AF. A major caveat in our analysis, however, is that hemostatic markers were measured at baseline, in many cases years before the clinical diagnosis of AF.

The present analysis has notable strengths, including the large sample, long follow-up, and detailed information on cardiovascular risk factors and events. Some limitations, however, affect our study. First, most AF cases were identified through hospital discharge codes. We and others have shown adequate specificity of hospital discharge codes of $\mathrm{AF}^{22,25}$ but cases identified and treated only in outpatient settings were probably missed. Additional indirect evidence of the validity of AF ascertainment in the ARIC study includes the similar incidence rates of $\mathrm{AF}$ in our cohort compared to other populations, ${ }^{22}$ and the strong and specific association of genetic variants in the $4 \mathrm{q} 25$ chromosomal region with the risk of AF in ARIC. ${ }^{37}$ Second, hemostatic markers were measured only once at baseline, introducing potential nondifferential measurement error in the exposure variables. Third, unmeasured or residual confounding could partly explain the results. For example, data on well-established biomarkers of $\mathrm{AF}$ such as $\mathrm{C}$-reactive protein or natriuretic peptides ${ }^{3,38}$ were not available in the ARIC cohort at baseline. Finally, we only assessed the association of AF with markers of hemostatic function available in the entire ARIC cohort.

In conclusion, we have shown that certain markers of hemostatic function, including fibrinogen, von Willebrand factor, factor VIIIc, protein C, and factor VIIc are associated with new-onset of AF independent of known risk factors for AF. Additionally, our results suggest that hemostatic markers might be useful in the risk assessment of patients with AF.

\section{Supplementary Material}

Refer to Web version on PubMed Central for supplementary material.

\section{Acknowledgments}

The authors thank the staff and participants of the ARIC study for their important contributions. The authors of this manuscript have certified that they comply with the Principles of Ethical Publishing in the International Journal of Cardiology. 39

FUNDING SUPPORT The Atherosclerosis Risk in Communities Study is carried out as a collaborative study supported by National Heart, Lung, and Blood Institute contracts N01-HC-55015, N01-HC-55016, N01-HC-55018, N01-HC-55019, N01-HC-55020, N01-HC-55021, and N01-HC-55022. This work was additionally supported by National Heart, Lung, and Blood Institute grant RC1HL099452 and American Heart Association grant 09SDG2280087.

\section{References}

1. Miyasaka Y, Barnes ME, Gersh BJ, et al. Secular trends in incidence of atrial fibrillation in Olmsted County, Minnesota, 1980 to 2000 , and implications on the projections for future prevalence. Circulation. 2006; 114:119-25. [PubMed: 16818816] 
2. Benjamin EJ, Chen P-S, Bild DE, et al. Prevention of atrial fibrillation: report from an NHLBI workshop. Circulation. 2009; 119:606-18. [PubMed: 19188521]

3. Aviles RJ, Martin DO, Apperson-Hansen C, et al. Inflammation as a risk factor for atrial fibrillation. Circulation. 2003; 108:3006-10. [PubMed: 14623805]

4. Wang TJ, Larson MG, Levy D, et al. Plasma natriuretic peptide levels and the risk of cardiovascular events and death. N Engl J Med. 2004; 350:655-63. [PubMed: 14960742]

5. Folsom AR, Wu KK, Rosamond WD, et al. Prospective study of hemostatic factors and incidence of coronary heart disease: the Atherosclerosis Risk in Communities (ARIC) Study. Circulation. 1997; 96:1102-8. [PubMed: 9286936]

6. Fibrinogen Studies Collaboration. Plasma fibrinogen level and the risk of major cardiovascular diseases and nonvascular mortality: an individual participant meta-analysis. JAMA. 2005; 294:1799-809. [PubMed: 16219884]

7. Sohara H, Amitani S, Kurose M, et al. Atrial fibrillation activates platelets and coagulation in a time-dependent manner: a study in patients with paroxysmal atrial fibrillation. J Am Coll Cardiol. 1997; 29:106-12. [PubMed: 8996302]

8. Issac TT, Dokainish H, Lakkis NM. Role of inflammation in initiation and perpetuation of atrial fibrillation. A systematic review of the published data. J Am Coll Cardiol. 2007; 50:2021-8. [PubMed: 18021867]

9. Mosnier LO, Zlokovic BV, Griffin JH. The cytoprotective protein C pathway. Blood. 2007; 109:3161-72. [PubMed: 17110453]

10. Cardin S, Li D, Thorin-Trescases N, et al. Evolution of the atrial fibrillation substrate in experimental congestive heart failure: angiotensin-dependent and - independent pathways. Cardiovasc Res. 2003; 60:315-25. [PubMed: 14613861]

11. Mukamal KJ, Tolstrup JS, Friberg J, et al. Fibrinogen and albumin levels and risk of atrial fibrillation in men and women (the Copenhagen City Heart Study). Am J Cardiol. 2006; 98:75-81. [PubMed: 16784925]

12. Schnabel RB, Larson MG, Yamamoto JF, et al. Relations of biomarkers of distinct pathophysiological pathways and atrial fibrillation incidence in the community. Circulation. 2010; 121:200-7. [PubMed: 20048208]

13. Wolf PA, Mitchell JB, Baker CS, et al. Impact of atrial fibrillation on mortality, stroke, and medical costs. Arch Intern Med. 1998; 158:229-34. [PubMed: 9472202]

14. Watson T, Shantsila E, Lip GYH. Mechanisms of thrombogenesis in atrial fibrillation: Virchow's triad revisited. Lancet. 2009; 373:155-66. [PubMed: 19135613]

15. Conway DSG, Pearce LA, Chin BSP, et al. Prognostic value of plasma von Willebrand factor and soluble P-selectin as indices of endothelial damage and platelet activation in 994 patients with nonvalvular atrial fibrillation. Circulation. 2003; 107:3141-5. [PubMed: 12796127]

16. Heeringa J, Conway DSG, Van der Kuip DAM, et al. A longitudinal population-based study of prothrombotic factors in elderly subjects with atrial fibrillation: the Rotterdam Study 1990-1999. J Thromb Haemost. 2006; 4:1944-9. [PubMed: 16824187]

17. Feng D, D'Agostino RB, Silbershatz H, et al. Hemostatic state and atrial fibrillation (the Framingham Offspring Study). Am J Cardiol. 2001; 87:168-71. [PubMed: 11152833]

18. The ARIC Investigators. The Atherosclerosis Risk in Communities (ARIC) study: design and objectives. Am J Epidemiol. 1989; 129:687-702. [PubMed: 2646917]

19. Papp AC, Hatzakis H, Bracey A, et al. ARIC hemostasis study, I: development of blood collection and processing system suitable for multicenter hemostatic studies. Thromb Haemost. 1989; 61:159. [PubMed: 2526384]

20. Atherosclerosis Risk in Communities Study Manual 9: Hemostasis Determinations. Chapel Hill, NC: National Heart, Lung, and Blood Institute of the National Institutes of Health, Collaborative Studies Coordinating Center, University of North Carolina; 1987.

21. Chambless LE, McMahon R, Wu K, et al. Short-term intraindividual variability in hemostasis factors. The ARIC Study. Ann Epidemiol. 1992; 2:723-33. [PubMed: 1342324]

22. Alonso A, Agarwal SK, Soliman EZ, et al. Incidence of atrial fibrillation in whites and AfricanAmericans: the Atherosclerosis Risk in Communities (ARIC) study. Am Heart J. 2009; 158:1117. [PubMed: 19540400] 
23. Chamberlain AM, Agarwal SK, Ambrose M, et al. Metabolic syndrome and incidence of atrial fibrillation among blacks and whites in the Atherosclerosis Risk in Communities (ARIC) Study. Am Heart J. 2010; 159:850-6. [PubMed: 20435195]

24. Soliman EZ, Prineas RJ, Case D, et al. Ethnic distribution of electrocardiographic predictors of atrial fibrillation and its impact on understanding the ethnic distribution of ischemic stroke in the Atherosclerosis Risk in Communities Study (ARIC). Stroke. 2009; 40:1204-11. [PubMed: 19213946]

25. Psaty BM, Manolio TA, Kuller LH, et al. Incidence of and risk factors for atrial fibrillation in older adults. Circulation. 1997; 96:2455-61. [PubMed: 9337224]

26. Rosamond W, Folsom AR, Chambless LE, et al. Stroke incidence and survival among middle-aged adults: 9-year follow-up of the Atherosclerosis Risk in Communities (ARIC) cohort. Stroke. 1999; 30:736-43. [PubMed: 10187871]

27. White AD, Folsom AR, Chambless LE, et al. Community surveillance of coronary heart disease in the Atherosclerosis Risk in Communities (ARIC) Study: Methods and initial two years' experience. J Clin Epidemiol. 1996; 49:223-33. [PubMed: 8606324]

28. Baecke JAH, Burema J, Fritjers JER. A short questionnaire for the measurement of habitual physical activity in epidemiological studies. Am J Clin Nutr. 1982; 36:936-42. [PubMed: 7137077]

29. Barac A, Campia U, Panza JA. Methods for evaluating endothelial function in humans. Hypertension. 2007; 49:748-60. [PubMed: 17309954]

30. Davignon J, Ganz P. Role of endothelial dysfunction in atherosclerosis. Circulation. 2004; 109:III-27-III-32. [PubMed: 15198963]

31. Meigs JB, O'Donnell CJ, Tofler GH, et al. Hemostatic markers of endothelial dysfunction and risk of incident type 2 diabetes. Diabetes. 2006; 55:530-7. [PubMed: 16443791]

32. López-Sagaseta J, Montes R, Puy C, et al. Binding of factor VIIa to the endothelial cell protein C receptor reduces its coagulant activity. J Thromb Haemost. 2007; 5:1817-24. [PubMed: 17723119]

33. Bae J-S, Yang L, Manithody C, et al. The ligand occupancy of endothelial protein C receptor switches the protease-activated receptor 1-dependent signaling specificity of thrombin from a permeability-enhancing to a barrier-protective response in endothelial cells. Blood. 2007; 110:3909-16. [PubMed: 17823308]

34. Li-Saw-Hee FL, Blann AD, Gurney D, et al. Plasma von Willebrand factor, fibrinogen and soluble P-selectin levels in paroxysmal, persistent and permanent atrial fibrillation. Effects of cardioversion and return of left atrial function. Eur Heart J. 2001; 22:1741-7. [PubMed: 11511124]

35. Folsom AR, Rosamond WD, Shahar E, et al. Prospective study of markers of hemostatic function with risk of ischemic stroke. Circulation. 1999; 100:736-42. [PubMed: 10449696]

36. Folsom AR, Ohira T, Yamagishi K, et al. Low protein C and incidence of ischemic stroke and coronary heart disease: the Atherosclerosis Risk in Communities (ARIC) Study. J Thromb Haemost. 2009; 7:1774-8. [PubMed: 19691480]

37. Benjamin EJ, Rice KM, Arking DE, et al. Variants in ZFHX3 are associated with atrial fibrillation in individuals of European ancestry. Nat Genet. 2009; 41:879-81. [PubMed: 19597492]

38. Patton KK, Ellinor PT, Heckbert SR, et al. N-terminal pro-B-type natriuretic peptide is a major predictor of the development of atrial fibrillation: the Cardiovascular Health Study. Circulation. 2009; 120:1768-74. [PubMed: 19841297]

39. Coats AJ. Ethical authorship and publishing. Int J Cardiol. 2009; 131:149-50. [PubMed: 19046787] 
A.

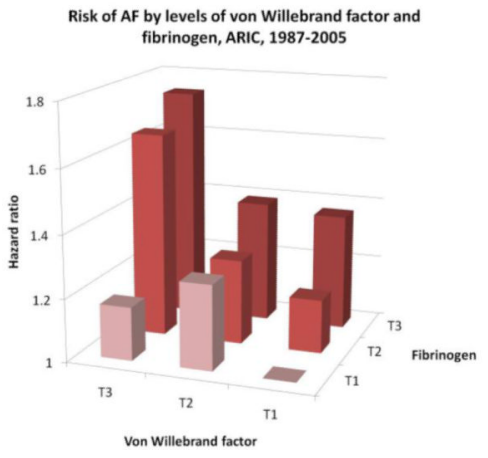

B.

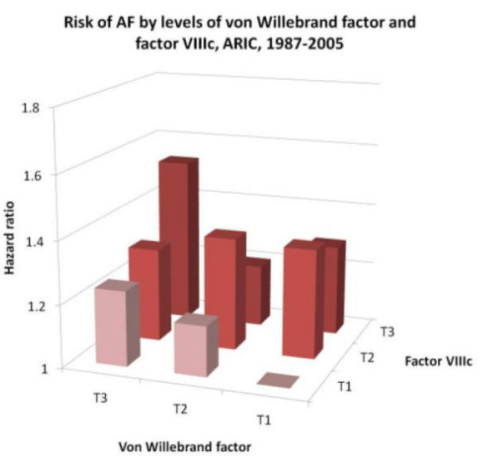

Figure 1.

Hazard ratio of atrial fibrillation by tertiles of von Willebrand factor and fibrinogen (A), and tertiles of von Willebrand factor and factor VIII activity (FVIIIc) (B), ARIC, 1987-2005. Cox proportional hazards model adjusted for age, race, gender, center, education, income, smoking, alcohol intake, sports-related physical activity, body mass index, height, left ventricular hypertrophy, systolic blood pressure, use of antihypertensive medications, diabetes, cholesterol meds, HDL-cholesterol, total cholesterol, and history of myocardial infarction or heart failure at baseline. 
Table 1

Baseline characteristics of study participants by race and atrial fibrillation incidence during follow-up, ARIC, 1987-1989

\begin{tabular}{|c|c|c|c|c|}
\hline & \multicolumn{2}{|c|}{ Whites } & \multicolumn{2}{|c|}{ African-Americans } \\
\hline & No AF & $\mathbf{A F}$ & No AF & $\mathbf{A F}$ \\
\hline $\mathrm{N}$ & 10131 & 976 & 3518 & 233 \\
\hline Age, years & $54.1(5.7)$ & $57.3(5.3)$ & $53.4(5.8)$ & $56.2(5.7)$ \\
\hline Women & 53.9 & 41.5 & 62.2 & 55.4 \\
\hline \multicolumn{5}{|l|}{ Education } \\
\hline Less than high school & 16.3 & 24.9 & 40.3 & 51.5 \\
\hline High school degree & 45.8 & 42.7 & 28.7 & 27.0 \\
\hline College & 37.9 & 32.4 & 31.0 & 21.5 \\
\hline Body mass index, $\mathrm{kg} / \mathrm{m}^{2}$ & $26.9(4.8)$ & $28.4(5.6)$ & $29.5(6.1)$ & $31.2(6.8)$ \\
\hline \multicolumn{5}{|l|}{ Smoking } \\
\hline Never & 41.0 & 30.8 & 46.0 & 42.9 \\
\hline Former & 34.8 & 39.9 & 24.2 & 22.8 \\
\hline Current & 24.2 & 29.3 & 29.8 & 34.3 \\
\hline Alcohol, g/week & $45.4(93.1)$ & $50.4(103.1)$ & $33.0(100.0)$ & $27.2(76.9)$ \\
\hline Sports-related physical activity & $2.5(0.8)$ & $2.5(0.8)$ & $2.2(0.7)$ & $2.1(0.6)$ \\
\hline Hypertension & 25.4 & 44.3 & 54.3 & 73.0 \\
\hline Diabetes & 8.4 & 15.7 & 18.2 & 33.9 \\
\hline Left ventricular hypertrophy & 0.8 & 2.9 & 5.3 & 9.0 \\
\hline History of myocardial infarction & 3.5 & 9.7 & 3.4 & 6.4 \\
\hline History of heart failure & 3.1 & 9.3 & 6.4 & 12.0 \\
\hline \multicolumn{5}{|l|}{ Hemostatic markers } \\
\hline von Willebrand factor, $\%$ & $111.3(42.6)$ & $124.5(46.4)$ & $132.4(55.6)$ & $148.9(67.5)$ \\
\hline Factor VIII activity, \% & $125.0(34.2)$ & $133.9(36.7)$ & $146.4(47.1)$ & $158.9(52.9)$ \\
\hline Fibrinogen, $\mathrm{mg} / \mathrm{dL}$ & $295.7(61.0)$ & $313.9(64.2)$ & $318.9(71.7)$ & $332.9(76.9)$ \\
\hline Factor VII activity, \% & $119.5(28.7)$ & $119.1(28.3)$ & $118.1(30.6)$ & $120.1(36.1)$ \\
\hline Antithrombin III, \% & $110.2(21.0)$ & $109.4(20.8)$ & $114.9(23.1)$ & $115.6(24.3)$ \\
\hline Protein $\mathrm{C}, \mu \mathrm{g} / \mathrm{mL}$ & $3.2(0.6)$ & $3.2(0.6)$ & $3.1(0.6)$ & $3.1(0.6)$ \\
\hline aPTT, seconds & $29.1(2.9)$ & $28.9(3.0)$ & $29.1(3.2)$ & $29.0(3.4)$ \\
\hline
\end{tabular}

aPTT: activated partial thromboplastin time. Values refer to percent or mean (standard deviation) 


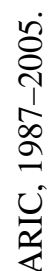




\section{Table 3}

Association of extreme levels of hemostatic markers with incidence of AF (hazard ratios and 95\% confidence intervals), ARIC, 1987-2005

\begin{tabular}{|c|c|c|}
\hline & \multicolumn{2}{|c|}{ Hazard ratio ( $95 \%$ confidence interval) } \\
\hline & $\geq$ p90 vs $<{\mathrm{p} 90^{*}}^{*}$ & $\geq$ p95 vs $<\mathrm{p95}^{*}$ \\
\hline \multicolumn{3}{|c|}{ Von Willebrand factor } \\
\hline Model 1 & $1.54(1.31-1.81)$ & $1.67(1.35-2.08)$ \\
\hline Model 2 & $1.36(1.15-1.60)$ & $1.40(1.12-1.74)$ \\
\hline Model 3 & $1.33(1.13-1.57)$ & $1.36(1.09-1.70)$ \\
\hline \multicolumn{3}{|c|}{ Factor VIIIc } \\
\hline Model 1 & $1.56(1.32-1.86)$ & $1.63(1.29-2.05)$ \\
\hline Model 2 & $1.29(1.08-1.54)$ & $1.30(1.03-1.64)$ \\
\hline Model 3 & $1.27(1.07-1.51)$ & $1.29(1.02-1.63)$ \\
\hline \multicolumn{3}{|c|}{ Fibrinogen } \\
\hline Model 1 & $1.61(1.36-1.90)$ & $1.78(1.43-2.21)$ \\
\hline Model 2 & $1.19(1.00-1.41)$ & $1.28(1.03-1.60)$ \\
\hline Model 3 & $1.17(0.98-1.38)$ & $1.26(1.01-1.58)$ \\
\hline \multicolumn{3}{|c|}{ Factor VIIc ${ }^{*}$} \\
\hline Model 1 & $1.10(0.91-1.32)$ & $1.15(0.89-1.47)$ \\
\hline Model 2 & $1.19(0.99-1.44)$ & $1.25(0.97-1.60)$ \\
\hline Model 3 & $1.21(1.01-1.47)$ & $1.26(0.98-1.62)$ \\
\hline \multicolumn{3}{|l|}{ ATIII } \\
\hline Model 1 & $1.09(0.90-1.32)$ & $1.13(0.88-1.46)$ \\
\hline Model 2 & $1.00(0.82-1.21)$ & $1.01(0.78-1.30)$ \\
\hline Model 3 & $0.99(0.81-1.20)$ & $1.00(0.77-1.29)$ \\
\hline \multicolumn{3}{|c|}{ Protein $C^{*}$} \\
\hline Model 1 & $1.11(0.93-1.34)$ & $1.31(1.06-1.61)$ \\
\hline Model 2 & $1.14(0.94-1.38)$ & $1.33(1.07-1.65)$ \\
\hline Model 3 & $1.12(0.93-1.36)$ & $1.29(1.04-1.59)$ \\
\hline \multicolumn{3}{|l|}{ aPTT } \\
\hline Model 1 & $0.92(0.75-1.12)$ & $0.96(0.73-1.26)$ \\
\hline Model 2 & $0.95(0.78-1.16)$ & $0.97(0.73-1.27)$ \\
\hline Model 3 & $0.94(0.77-1.15)$ & $0.96(0.73-1.26)$ \\
\hline
\end{tabular}

aPTT: activated partial thromboplastin time; ATIII: antithrombin III

Model 1: Cox proportional hazards model adjusted for age, race, and gender

Model 2: As model 1, additionally adjusted for center, education, income, smoking, alcohol intake, sports-related physical activity, body mass index, height, left ventricular hypertrophy, systolic blood pressure, use of antihypertensive medications, diabetes, cholesterol meds, HDLcholesterol, and total cholesterol

Model 3: As model 2, additionally adjusted for history of myocardial infarction or heart failure at baseline 
For protein $\mathrm{C}$ and factor VIIc, the exposed are defined as those with levels $\leq 10^{\text {th }}$ (first column) and $\leq 5^{\text {th }}$ (second column) percentiles. 


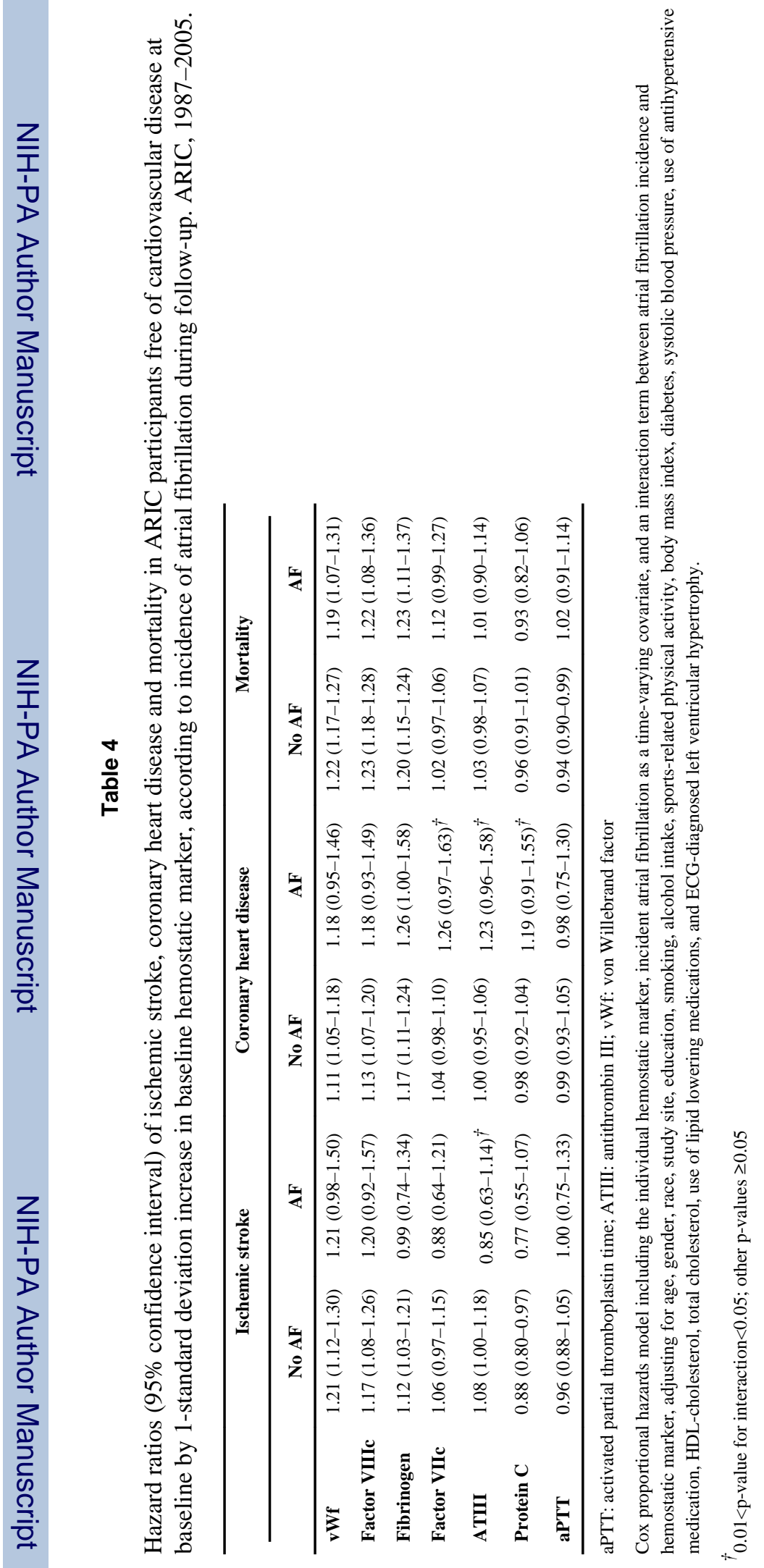

